\title{
Evaluating Structured Group Activities for the Large Class
}

\section{John Stevenson}

The University of Rhode Island

I teach a 500-student introductory course in a large lecture hall with a microphone and an overhead projector. For many students this is a first semester course; often it is taken to fulfill a requirement although there is usually some interest in the subject matter (psychology). I am not a particularly charismatic speaker. From the back of the classroom I look antsize, and my voice rattles, disembodied, from the loudspeakers. Despite this, I want to use class time effectively to give students not only exposure to concepts but practice in using them. I believe memorized factual material will be of little lasting value unless tied to students' ways of thinking and problem-solving in their worlds. For that reason, I want to provide students with structured opportunities to think critically about course content issues and to master and internalize concepts by collaborating in their application. I also want my students to become intrigued enough to want to learn more about psychology.

I wanted to see if, in a class of 500 , I could provide students with opportunities to discuss concepts with one another, apply concepts to practical problems, explore together the value implications of what they were learning, and critque conclusions drawn from previous research. Further, I wanted to know if students would respond positively to such opportunities when they were not directly tied to examinations, or would only appreciate activities that obviously provided practice relevant to tests.

From To Improve the Academy: Resources for Student, Faculty, and Institutional Development, Vol. 7. Edited by J. Kurfiss, L. Hilsen, S. Kahn, MD. Sorcinelli, and R. Tiberius. POD/New Forums Press, 1988. 


\section{Method}

As one means to respond to those challenges, I developed a semesterlong series of structured small-group activities to be undertaken in the large classroom. There were two kinds of activities: "involvement" and "practice." For both kinds, the class was asked to divide into groups of two or three students and given a concrete, two-to-five-minute task and a product to generate, usually on a piece of paper to be signed by all group members and turned in. The task was presented via the overhead projector. Involvement tasks ordinarily occurred near the beginning of class and entailed questions or challenges without right or wrong answers (e.g., making up items for a campus stress scale). Practice tasks initially occurred near the end of class and called for answers to non-memorization questions that might appear on an examination (e.g., deciding which types of psychologist would engage in several provided examples of activities). In response to student feedback, practice tasks were redesigned to be conducted at the beginning of class, with the answers reviewed at the end of class. Often, I gave feedback to the class regarding their responses to the tasks. This was sometimes done immediately by taking a show of hands or brief oral answers. At other times, feedback was given in the form of a report by me in the next class, based on the written products turned in by students. Their products were never graded.

I wanted to know whether these alternative uses of class time were having some impact on my students and I wanted feedback to improve my exercises. Since I could not randomly assign some of my students to small group activities while the rest got only a conventional lecture, I chose to randomly assign topics within the course to different treatments. My survey course covers an eighteen chapter textbook, each chapter treating a standard psychology topic, progressing from the biological to the social end of psychology. So I simply divided the course into thirds and randomly assigned the six topics covered in each third to one of three treatments: involvement, practice, or conventional lecture.

To assess the effects of the activities on students, I planned three general sources of information: (1) ratings by students of individual activities, collected at the end of the class period in which the activity was conducted; (2) retrospective recall and ratings by students at the end of the semester; and (3) performance on final examination questions. The ratings collected after each activity were on a one-to-ten rating scale with one least favorable and ten most favorable. The ratings were accompanied by two qualitative questions: "What caused you to rate it as highly as you did?" and "What kept you from rating it higher?" Results from each administration of this form were reported back to me within a week so that 
I could respond to them in planning subsequent activities. At the end of the semester, students were given a questionnaire that asked them to (1) indicate their interest in learning more about each topic covered in the course; (2) recall activities that stood out as good or bad; (3) rate their frequency and intensity of participation in group activities (4) suggest the optimal frequency of practice and involvement activities; and (5) rate the small group activities as a whole on a one-to-ten scale. I also intended to derive subscores by topic and treatment from the final, but I have not done that rescoring.

\section{Results}

First, how did students react to the activities immediately after each was conducted? Due to the logistical difficulties associated with frequent surveys of a class of 500 , only four of six "involvement" and three of six "practice" activities were actually evaluated in this way. The class ratings of involvement activities ranged from 6.19 to 8.05 , with a mean of 7.23 . The range for practice activities was from 6.54 to 6.98 , with a mean of 6.83 . Qualitative comments ranged from very positive ("gives good practice for exams," "makes lecture material more interesting") to very negative ("a boring waste of time," "too easy," "too hard to understand"), but one set of comments was very consistent: students found activities placed at the end of class unhelpful - they felt rushed and had trouble concentrating on the task or my post-task commentary.

At the end of the semester, what were students' retrospective reactions? Students were asked first to read a list of the eighteen topics which had been treated in the course and to indicate their interest in each by circling any of the following: A) "If I had time, I'd like to take another course about this." B) "I wish we had spent more class time on this." C) "I'd like to read more about this." D) "I found this generally interesting but don't have any particular interest in following it up in any way." They were instructed to circle as many responses (from none to four) as they wished for each topic. Table 1 presents the proportions of students who circled each response to each topic, with the topics grouped by treatment. Topics associated with involvement activities seem to have generated the most interest, closely followed by topics treated by conventional lectures. Topics associated with practice activities were least likely to be found interesting. Asked to think back on the 10-12 exercises tried in class and to list any which stood out as good or bad, students were more than twice as likely to name involvement activities than practice activities as good, and much more likely to name practice than involvement activities as bad. Al- 
TABLE 1

Mean Percentages of 229 Students Indicating Interest in Course Topics Grouped By Experimental Treatment

\begin{tabular}{lccr}
\hline & \multicolumn{3}{c}{$\begin{array}{c}\text { Experimental Treatment } \\
\text { During Topic }\end{array}$} \\
\hline \multicolumn{1}{c}{ Type of Interest } & Involvement & Practice & Lecture \\
\hline Would take another course & $25 \%$ & $18 \%$ & $21 \%$ \\
Would prefer more class time & $27 \%$ & $23 \%$ & $27 \%$ \\
Would like to read more & $31 \%$ & $28 \%$ & $31 \%$ \\
Interesting, no more follow-up & $33 \%$ & $29 \%$ & $33 \%$
\end{tabular}

TABLE 2

End-of-Semester Ratings of Preferred Frequencies of Involvement and Practice Small Group Exercises

Type of

Preferred frequency

\begin{tabular}{lccccc}
\cline { 2 - 6 } Exercise & Every class & Weekly & Bi-weekly & Monthly & Never \\
\hline Involvement & 48 & 93 & 46 & 18 & 8 \\
Practice & 51 & 111 & 34 & 10 & 7 \\
\hline
\end{tabular}

though they were not among the 10-12 exercises I had in mind, students also listed a few of the classroom demonstrations that were part of the "conventional lecture" treatments. Overall, 126 of the 229 students responding to the questionnaire recalled at least one activity as good and 78 listed at least one as bad.

Students were also asked how frequently the two types of activity should be done in my lecture class. Their responses are summarized in Table 2. A large majority of them indicated that involvement and practice exercises should be done at least weekly, with the practice activities somewhat more likely than involvement activities to be preferred at least weekly. The most common recommendation for frequency of in-class discussions was weekly.

Finally, students were asked for an overall rating of the various small group activities tried in class over the semester. On the same 10-point scale used during the semester, their mean rating was 6.63 , with a standard 
deviation of 1.91. That retrospective rating was somewhat lower than the average of the ratings given during the semester.

\section{Discussion}

Feedback from students has already had some impact, and knowledge gained from the project has additional implications for the future. The timing of discussion activities was crucial. The most effective approach was to structure the activity so that it could be conducted near the beginning of a class, with a follow-up at the end of the class. This was difficult for me at times, since I wanted the activities to serve as a chance for critiquing, reviewing, and practicing applications of lecture content. However, feedback indicated that students found the end-of-class timing so aversive that the pedagogical advantages of the early-in-class timing clearly outweighed the disadvantages.

From the data collected at the end of the semester it appears that involvement activities may have somewhat more impact on students' subsequent interest in a topic, and students are more likely to recall those activities as positive experiences. However, when asked how often they would like involvement and practice activities, they were somewhat more interested in frequent practice. Coming shortly before the final examination, a question about preferred frequency of practice may have struck a particularly responsive chord.

Two sources of complexity make it unwise to come down firmly for or against group activities in general and for involvement versus practice. The first complexity is that each use of class time appears to have strengths and weaknesses. Practice may help with examinations and be reassuring in that sense, but may be less likely to leave a vivid, lasting impression of the significance of the content. Involvement is more memorable and interest-enhancing, but not so relevant for test preparation. Conventional lectures, especially with the kinds of demonstrations and dramatic examples I use, allow more controlled, systematic presentation of the subject matter. Secondly, students vary widely in their goals for survey courses and in the ways they prefer to learn. The most striking quality of the written feedback I received was its variability. For some students a chance to discuss issues related to the course with other students was a wonderful opportunity. For others it was a needless distraction, not at all helpful. Some students didn't need such activities to grasp the issues and concepts, and for them more lecture seemed preferable. Others were angered and bewildered by being asked to discuss content they did not understand, and they also preferred lectures. Apparently there are no right answers to my 
seemingly straightforward questions and this frustrates me almost as much as it frustrates my students. Instead of answers, I am left with more sophisticated questions and a clearer sense of the inherent difficulty of what I am attempting to accomplish in my classroom.

\section{Reflections on classroom research}

Asking students to provide extensive quantitative and qualitative feedback on a pedagogical innovation in my classroom was an instructive experience. I was forced to try to specify my objectives more clearly than I liked, and to plan my classroom activities more systematically and conscientiously than is usual. I was subjected to bi-weekly pages of students' qualitative comments, some laudatory and some just plain nasty. I had the delightful opportunity to work collaboratively with colleagues committed to teaching, both those helping directly in designing and conducting this project and those struggling with their own projects. I discovered how annoyed many students were that I wanted to keep asking them for feedback - it was not part of what they defined as their classroom responsibility, and it was widely viewed as an imposition. I found the experience stimulating, a good way to keep my creative juices flowing, but also frustrating, a time when my imperfections and my students' heterogeneity were brought home with quantitative precision and qualitative vividness.

As a teacher I am not primarily focused on making my courses suitable for rigorous research, and the requirements of even the relatively benign, non-experimental project reported here were sometimes onerous. Special timing constraints and classroom logistics were added onto my already complex task in the classroom. Despite this, and despite the pain associated with renewed awareness of my fallibility, I learned a good deal from the experience, and I believe it benefited both the class in which I conducted the project and my future sallies into the large-classroom-introductory-course. I intend to continue experimenting with small group activities and will at some point want to take another systematic look at their impact. I tell my students that learning requires risk-taking. My own learning ought be no exception. 